Article

\title{
Investigating the Spatial Heterogeneity and Correlation Network of Green Innovation Efficiency in China
}

\author{
Ke-Liang Wang * and Fu-Qin Zhang
}

check for

updates

Citation: Wang, K.-L.; Zhang, F.-Q Investigating the Spatial

Heterogeneity and Correlation

Network of Green Innovation

Efficiency in China. Sustainability

2021, 13, 1104. https://doi.org/

$10.3390 /$ su13031104

Received: 17 December 2020

Accepted: 18 January 2021

Published: 21 January 2021

Publisher's Note: MDPI stays neutral with regard to jurisdictional claims in published maps and institutional affiliations.

Copyright: (c) 2021 by the authors Licensee MDPI, Basel, Switzerland. This article is an open access article distributed under the terms and conditions of the Creative Commons Attribution (CC BY) license (https:/ / creativecommons.org/licenses/by/ $4.0 /)$.
School of Economics, Ocean University of China, Qingdao 266100, China; zhangfuqin@stu.ouc.edu.cn

* Correspondence: wkl@ouc.edu.cn

\begin{abstract}
With environmental problems becoming increasingly serious worldwide, scholars' research views on innovation have begun to pay more attention to the technological value from an ecological perspective, instead of simply analyzing the importance of technological innovation from the perspective of economic value. Currently, improving green innovation efficiency (GIE) has been considered as a critical path to realizing economic transformation and green development. Based on the global Super-Epsilon-based measure (EBM) model, Moran index, vector autoregression (VAR) model, and block model, this study investigated the temporal and spatial characteristics of GIE in 30 provinces in China from 2009 to 2017, and analyzed the spatial heterogeneity and spatial correlation network characteristics. The results showed that in spatial terms, China's GIE presented an extremely unbalanced development model. In provinces with a higher GIE, there was an overall improvement of GIE, but there was a lower impact in provinces with a lower GIE. The efficiency of China's green innovation could be divided into four blocks. The first block was the main overflow, the second block was the broker, the third block was the bilateral spillover, and the fourth block was the net benefit. The four blocks had their own functions, and a very significant correlation was observed among them.
\end{abstract}

Keywords: GIE; super-EBM model; spatial autocorrelation analysis; block models

\section{Introduction}

Since the reform and opening up, China's economy has maintained rapid growth [1], and China's GDP as a proportion of the world's total economy has continued to rise, ranking second in the world [2]. However, in recent years, the growth rate of China's economy has begun to slow down, and China's economic development has entered a "New Normal" [3-5]. Economic growth has shifted from high speed to medium-high speed, the economic structure has been optimized and upgraded, and it has shifted from factor-driven and investment-driven to innovation-driven [6]. For national development, technological innovation is an important driving force for social development [5]. Currently, China's economic development and technological innovation capabilities are at the world advanced level, but while achieving rapid economic development in the past, the development model of high pollution, high energy consumption, and low efficiency has exerted a huge impact on the ecological environment [7]. Conversely, environmental pollution and ecological destruction will also hinder economic development [8]. How to realize the coordinated development of the economy and the ecological environment is the biggest problem facing China. In October 2015, Chinese President Xi Jinping proposed five principles of development: innovation, coordination, greening, opening up, and sharing [9]. This innovation process assumes a key role for environmental sustainability and productivity [10,11]. Green innovation, as an important part of technological innovation, closely centering on China's two development concepts, green and innovation, has become an important force in promoting the transformation of economic development mode and solving environmental problems [12]. Green innovation has played a vital role in promoting China's sustainable development $[13,14]$. 
Green innovation efficiency is an efficiency measure of the green innovation inputoutput. It measures the level of innovation within environmental pollution control and energy consumption, and represents a green index of innovation quality [15]. Regional green innovation efficiency (GIE) can be used to assess the quality of a region's green innovation activities under economic development and environmental constraints. Improving GIE plays a very important role in achieving green development in a region [16]. Measuring the efficiency of green innovation and examining its spatial differences and spillover characteristics can be effective ways to promote the improvement of China's green innovation level.

Theoretically speaking, based on the spatial heterogeneity analysis of green innovation efficiency, this paper uses 30 provinces in China as network nodes, and uses Granger causality test analysis to determine the spatial correlation relationship. In addition, based on social network analysis, this paper analyzes the structural characteristics of the spatial correlation network of China's green innovation efficiency in order to better understand the status and role of China's provinces in the spatial correlation network of green innovation development. This expands and supplements the ideas, methods, and analytical framework of green innovation study and provides a theoretical basis for research on green innovation efficiency and the development of green innovation in various regions. In a practical sense, from the perspectives of relational data and network analysis, this paper makes a clearer judgment of the correlation between green innovation efficiency in different provinces and reveals the overall characteristics of the correlation network structure of green innovation efficiency in China. This aims to reduce the difference in green innovation efficiency between regions and promote the sustainable and coordinated development of green innovation between regions.

There have been many studies on green innovation efficiency, but most of them focus on the measurement of green innovation efficiency. Research on the spatial effects of green innovation efficiency is limited to the perspective of spatial pattern. So, there are still two limitations in the following aspects. First, in the measurement of green innovation efficiency, the most commonly used methods are stochastic frontier analysis [17] and non-parametric methods represented by data envelopment analysis (DEA), such as the DEA-RAM model [18], slacks-based measure (SBM) model [19], and Super-Epsilonbased measure (EBM) model [20]. They lack a measurement method that combines superefficiency models with DEA environmental technology. Second, in terms of the spatial characteristics of green innovation efficiency, existing studies only illustrate the spatial differences in green innovation efficiency [21,22]. As for the reasons for this difference, no more in-depth research has been conducted. So, there is a lack of analysis from the perspective of spatial correlation networks.

This study makes the following contributions to the existing literature. (1) Based on the analysis of the spatial characteristics and heterogeneity of China's green innovation efficiency, this paper studies the temporal and spatial evolution characteristics of green innovation efficiency between different provinces through the temporal and spatial transition measurement method, which is an extension of existing research. (2) Existing studies are based on attribute data rather than relational data. For the first time, this paper re-examines the spatial correlation of China's green innovation efficiency from a relational perspective, and uses social network analysis and research paradigms to comprehensively deconstruct the overall network structure characteristics and evolutionary laws of China's regional green innovation spatial correlation. (3) This paper introduces the block model into the spatial correlation analysis of green innovation efficiency for the first time, divides China's green innovation efficiency into different blocks, judges the role of each block, and analyzes the spatial correlation between different blocks. So, we can grasp the regional role positioning and division of labor as a whole, and provide a basis for the targeted formulation of regional green innovation development policies.

The remainder of this paper is structured as follows: Section 2 presents the literature review; Section 3 explains the research methods; Section 4 analyzes the spatial heterogeneity 
of GIE; Section 5 analyzes the spatial correlation network of GIE; Section 6 concludes with the main findings and policy implications.

\section{Literature Review}

The key to the development of green innovation lies in improving GIE, i.e., improving the quality of green innovation development. Previous studies of GIE can be separated into the following two distinct categories:

(1) Studies of the measurement of green innovation efficiency: The measurement of innovation efficiency originated from the stochastic frontier analysis (SFA) method proposed by Farrell (1957) [23]. Bai and $\mathrm{Li} \mathrm{(2011)} \mathrm{and} \mathrm{Bai} \mathrm{(2013)} \mathrm{used} \mathrm{this} \mathrm{method} \mathrm{to} \mathrm{analyze} \mathrm{the}$ regional differences and influencing factors of China's innovation efficiency $[24,25]$. Subsequently, DEA was applied to the measurement of innovation efficiency [26,27]. Stochastic frontier analysis and data envelopment analysis are the main methods for measuring innovation efficiency. The measurement of GIE is different from the measurement of traditional innovation efficiency. It also considers undesired outputs, such as environmental pollution, within the basis of innovation efficiency. Efficiency measurements that consider such undesired outputs mainly include the following processing methods. The first is to regard environmental pollution as an environmental input and measure it through traditional efficiency measurement methods. The second is to conduct a linear transformation on the undesired output to measure the negative consequence of the undesired output. The third is to measure GIE through efficiency measurement models based on an undesired output, such as the slacks-based measure (SBM) [19,28] and EBM [20], while ensuring that the nature of the undesired output remains unchanged. Zhang et al. (2015) comprehensively considered the radial and non-radial features, combined with the Luenberger index, to measure the green production process that includes the undesired output and overcome the shortcomings of the traditional Charnes, Cooper, and Rhodes (CCR) and SBM models [29]. Tao et al. (2016) used the SBM model to measure the efficiency of China's green economy based on a consideration of $\mathrm{CO}_{2}$ emissions and energy consumption [30]. Liu et al. (2020) used the improved SBM model to measure the efficiency of China's green technology innovation based on environmental pollution and innovation failure [6].

(2) Studies of the factors influencing green innovation efficiency: As for the influencing factors of innovation efficiency, existing studies have mainly focused on input-output variables such as R\&D personnel input, R\&D expenditure input, and innovation output [26,31], and innovation environment variables such as innovation network size [27]. Studies have considered both the external and internal factors affecting GIE. The external factors are mainly government policies and market demand. When the level of green innovation and the efficiency is low, government policies are needed to promote the development of green innovation, which is mainly reflected in environmental regulations [28]. Many studies support this view. Oltra and Saint (2009) and Chiou et al. (2011) found that the main factors influencing corporate green innovation are environmental policy and technological stimuli [32,33]. Demirel and Kesidou (2011) found that environmental regulations have different impacts on different types of green innovation through their studies of British green innovation [34]. Although government policies can promote the development of regional green innovation, it is necessary to consider the development of the region itself when formulating policies. In the early stage of green innovation development, government regulations will increase costs and reduce economic benefits. However, as the level of green innovation development increases, government regulations will reduce the efficiency of resource allocation and weaken the role of regional internal funds to promote green innovation development [35]. Lin et al. (2013) found through research on the Vietnamese motorcycle industry that market demand can promote the development of green innovation [36]. As research has progressed, studies of the external factors influencing green innovation have become more abundant. The national competitive environment [37], information sharing [38], foreign investment [39], the behavior of multinational companies [40], and industrial agglomeration [41] will all affect the development of green innovation. Stud- 
ies of the internal factors influencing GIE have mainly been conducted from the perspective of enterprises. Enterprises are rational economic actors, and the development of green innovation is directly related to corporate profits. Green orientation is the cognitive stage in which companies implement environmental protection, and the improvement of green orientation will promote green innovation cooperation between enterprises, customers, and suppliers [42].

There have been relatively few studies of the spatial characteristics of GIE. Compared with the calculation of GIE and studies of the factors influencing GIE, there is a need for spatial research. Most existing studies have focused on the spatial characteristics of green development and green innovation. For example, Fu et al. (2016) analyzed the spatial pattern of green innovation in China. Overall, there was a significant positive spatial autocorrelation between different provinces, the spatial pattern of green innovation was stable, and the provinces with the best development levels were mainly concentrated in the southeast coastal areas, while the provinces in the northeast and central regions had weaker agglomeration effects [43]. Che et al. (2018) used the Super-SBM model to measure the efficiency of green development in China, and examined the spatial characteristics of green development efficiency in terms of spatial heterogeneity, spatial correlation, and its spatial mechanism [44].

Existing studies have shown that there are regional differences in GIE [45-47]. However, in terms of the spatial characteristics of GIE, a range of different results have been obtained by different studies. Du et al. (2019) used the shared input two-stage network DEA to measure the efficiency of green technology innovation in regional enterprises, and found that there were obvious regional imbalances and differences in GIE among Chinese industrial enterprises [48]. The efficiency of the eastern and western regions was higher than that of the central region, with the lowest efficiency occurring in the northeast region.

Chinese and international researchers have conducted in-depth research on green innovation from different perspectives, but there are still some shortcomings. Most of the research has been conducted from the perspective of industry [49] and enterprises [50]. Although researchers have analyzed the spatial characteristics of GIE from a regional perspective, they have also studied the spatial distribution characteristics of GIE, and several differences in the spatial distribution characteristics have been reported among the different studies [45]. Du et al. (2019) used a shared input two-stage network DEA to measure the efficiency of green technological innovation among regional enterprises and found that there were obvious regional imbalances and differences in the GIE of Chinese industrial enterprises [48]. The efficiency of the eastern and western regions was higher than that of the central region, while the efficiency was lowest in the northeast. However, Luo and Liang (2016) also used DEA to measure the overall green technology innovation efficiency of industrial enterprises in various regions of China, and found that the eastern region had the highest GIE, followed by the central and western regions [45]. To overcome the deficiencies of previous studies, the present study introduced a social network analysis to analyze the spatial correlation network characteristics of China's GIE. Social network analysis is an interdisciplinary analysis method for network relationships, which has been widely used in the fields of economics and management $[6,19,51,52]$. The social network analysis method was selected to study China's GIE based mainly on the following reasons [19]. First, the social network analysis method is an appropriate scale for spatial attribute data and has more analytical value. Second, the social network analysis method analyzes GIE from an overall perspective, which avoids the definition of proximity by spatial measurement. Third, the social network analysis method can reflect the overall characteristics of the spatial correlation of China's GIE, and analyze the role and positioning of each province in the spatial correlation network of GIE. 


\section{Methodology}

\subsection{Global Super-Epsilon-Based Measure Model with Undesirable Outputs}

In this study, the DEA approach was employed to measure GIE. Regarding the selection of DEA models, two categories with different features can be considered: radial and non-radial measures [53]. Among them, the radial measure is represented by the CCR model, the main shortcoming of which is the neglect of non-radial slacks when measuring efficiency. The slacks-based measure model (SBM) proposed by Tone (2002) [54] represents the non-radial measure, and it aims to obtain maximum rates of reduction in inputs, relaxing the proportionality and allowing independent changes to associated slacks [55]. However, the SBM model also has an inherent weakness in that its projected decisionmaking unit (DMU) may lose proportionality with the original input, which may lead to the loss of important information, and is inappropriate for the analysis. To sum up, both the radial and the non-radial model have merits and shortcomings. To make full use of the advantages and overcome the shortcomings of the two efficiency measures, Tone and Tsutsui (2010) [56] developed a hybrid distance model, the EBM model, which incorporates the merits of both radial and non-radial measures into a unified framework.

It is assumed that there are $N$ DMUs, and each DMU uses $L$ input factors, $x=$ $\left(x_{1 j}, x_{2 j}, \cdots, x_{L j}\right)$ and generate $\mathrm{M}$ desirable outputs, $y=\left(y_{1 j}, y_{2 j}, \cdots, y_{M j}\right)$, and $I$ undesirable outputs, $b=\left(b_{1 j}, b_{2 j}, \cdots, b_{I j}\right)$. The output-oriented EBM model can be described as follows:

$$
\begin{aligned}
& \min \frac{1}{\varphi+\varepsilon \sum_{r=1}^{M} \frac{w_{r}^{+} s_{r}^{+}}{y_{r 0}}} \\
& \text { s.t. }\left\{\begin{array}{l}
\sum_{j=1}^{N} \lambda_{j} x_{i j} \leq x_{i 0} \\
\sum_{j=1}^{N} \lambda_{j} y_{r j}-\varphi y_{r 0}-s_{r}^{+}=0 \\
\lambda \geq 0, s^{+} \geq 0, j=1, \cdots, N ; \\
i=1, \cdots, L ; r=1, \cdots, M
\end{array}\right.
\end{aligned}
$$

where $\omega_{r}^{+}$stands for the weight of output $\mathrm{r}$ and meets the condition of $\sum_{r=1}^{M} w_{r}^{+}=1\left(w_{r}^{+}>0\right)$; $\lambda$ is the intensity vector; $s_{r}^{+}$denotes the non-radial output slacks; the subscript " 0 " represents the DMU to be evaluated; $\varepsilon$ represents the relative importance of the non-radial slacks over the radial $\varphi$. $\varepsilon$ ranges between 0 and 1 , and when $\varepsilon$ is equal to 0 , the model is equivalent to the radial model, while when $\varepsilon$ is equal to 1 , the model denotes the non-radial model. In order to show the trend of GIE with time and make it comparable with the DMU with an efficiency score of 1 , global frontier and super efficiency approaches are introduced in the EBM model. When undesirable output is considered, the global Super-EBM model can be expressed as follows:

$$
\begin{aligned}
& \min \frac{1}{\varphi+\varepsilon \times \frac{1}{2}\left(\sum_{t=1}^{T} \sum_{m=1}^{M} \frac{w_{w}^{y} s_{m y}^{t}}{y_{m 0}^{t}}+\sum_{t=1}^{T} \sum_{k=1}^{I} \frac{w^{b} b^{t} t}{b_{k 0}^{t}}\right)} \\
& \text { s.t. }\left\{\begin{array}{c}
\sum_{t=1}^{T} \sum_{j=1}^{N} \lambda_{j}^{t} x_{i j}^{t} \leq x_{i 0}^{t}, i=1, \cdots, L ; j=1, \cdots, N \\
\quad \neq 0 \\
\sum_{t=1}^{T} \sum_{j=1}^{N} \lambda_{j}^{t} y_{m j}^{t}-\phi y_{m 0}^{t}-s_{m y}^{t}=0, m=1, \cdots, M \\
\quad \neq 0 \\
\sum_{t=1}^{T} \sum_{j=1}^{N} \lambda_{j}^{t} b_{k j}^{t}-\phi b_{k 0}^{t}+s_{k b}^{t}=0, k=1, \cdots, I \\
\quad \neq 0 \\
\lambda \geq 0, s_{k}^{b} \geq 0, s_{m}^{y} \geq 0 ; t=1, \cdots, T
\end{array}\right.
\end{aligned}
$$


where $x_{i j}^{t}, y_{m j}^{t}$, and $b_{k j}^{t}$ stand for the $i$ th input, $m$ th desirable output, and $k$ th undesirable output, respectively, of the $j$ th DMU at time $t ; w_{m}^{y}$ and $w_{k}^{b}$, respectively, denote the weights of desirable output and undesirable output variables, and they meet the condition of $\sum_{m=1}^{M} w_{m}^{y}=1, \sum_{k=1}^{I} w_{k}^{b}=1\left(w_{m}^{y} \geq 0, w_{k}^{b} \geq 0\right) ; s_{m y}^{t}$ and $s_{k b}^{t}$ refer to the slacks of the desirable output $\mathrm{m}$ and undesirable output $\mathrm{k}$, respectively.

\subsection{Spatial Correlation Analysis}

A spatial correlation analysis is essentially an analysis of the spatial interaction characteristics between different regions. According to the first law of geography, the closer the geographic distance between two regions, the stronger their spatial dependence [57]. To measure the spatial dependence between different provinces, the Moran index was used to analyze the spatial correlation. Spatial correlation is divided into global and local spatial autocorrelation. The corresponding measurement methods are the global and local Moran indexes. The specific calculations are as follows:

$$
\begin{aligned}
\text { Global Moran's } I & =\frac{n \sum_{i=1}^{n} \sum_{j=1}^{n} \omega_{i j}\left(x_{i}-\bar{x}\right)\left(x_{j}-\bar{x}\right)}{\sum_{i=1}^{n} \sum_{j=1}^{n} \omega_{i j} \sum_{i=1}^{n}\left(x_{i}-\bar{x}\right)^{2}} \\
\text { Local Moran's } I & =\frac{n\left(x_{i}-\bar{x}\right) \sum_{j=1}^{n} \omega_{i j}\left(x_{j}-\bar{x}\right)}{\sum_{i=1}^{n}\left(x_{i}-\bar{x}\right)^{2}}
\end{aligned}
$$

where $\omega_{i j}$ is the spatially weighted matrix, $n$ is the total number of samples, $x_{i}$ and $x_{j}$ are the sample values, and $\bar{x}$ is the sample mean. In addition, the value ranges of the global and local Moran indexes are both $[-1,1]$.

\subsection{Social Network Analysis}

\subsubsection{Spatial Correlation Network}

The spatial correlation network of GIE can reflect the internal connections within China's regional GIE. In the spatial correlation network, the dots in the network represent the 30 provinces in China, and the lines in the network represent the spatial correlations of GIE between the different provinces. This combination of dots and lines is the spatial correlation network. When constructing a spatial correlation network, it is first necessary to test the stationarity of provincial time series data through an Augmented Dickey-Fuller (ADF) test. Then, under the premise of ensuring data stability, an unstructured vector autoregression (VAR) was established between the two provinces [58], and the optimal lag period was determined. Finally, a Granger causality test was applied to determine the correlation between different provinces [19]. If the relationship between provinces passed the test, and a province had a significant impact on another province, then a directed arrow was drawn to indicate the relationship. Through Granger causality tests between two provinces, a spatial correlation network diagram reflecting the mutual influence between provinces was established.

\subsubsection{Characterization of the Spatial Correlation Network}

(1) Network Density

Network density can be used as an indicator of the strength of the correlation between different provinces. In a spatial correlation network, the number of correlations and the network density have a significant positive correlation, i.e., the greater the number of relationships, the greater the network density [51]. The specific formula used to calculate network density is as follows:

$$
D=\frac{L}{N(N-1)}
$$


where $D$ is the network density, $L$ is the number of relationships that actually exist in the spatial correlation network, and $N$ is the number of provinces in the spatial correlation network. The range of network density is $[0,1]$.

(2) Centrality Analysis

Centrality analysis focuses on the status and role of the social network. The more central a province is in the social network, the greater its influence on other provinces. The main indicators used to characterize centrality are the degree centrality, betweenness centrality, and closeness centrality $[51,55]$.

Degree centrality $\left(D_{e}\right)$ refers to the ratio of the number of provinces directly correlated with a province to the number of provinces in the spatial correlation network. The formula used for its calculation is as follows:

$$
D_{e}=\frac{n}{N-1}
$$

where $D_{e}$ is the degree centrality, $n$ is the number of provinces directly related to the province, and $N$ is the number of provinces in the spatial correlation network.

Betweenness centrality $\left(B_{c}\right)$ refers to the degree to which a province is in the central position in a spatial correlation network [59]. The higher the value, the stronger the relationship between this province and other provinces, and the more centrally it is located in the spatial correlation network.

Closeness centrality $\left(C_{c}\right)$ refers to the degree to which a province is not affected by other provinces in the spatial correlation network. The higher the value, the higher the influence of the province on other provinces, and the more likely it is to be the central actor in the spatial correlation network.

\subsection{Block Models}

Block model analysis was first proposed by White et al. (1976) [60] to analyze social network relationships. According to block model theory, the position of each province in a spatial correlation network can be analyzed [61]. There are four forms of this positional relationship. The first is the bilateral spillover block. The main characteristic of this block is that it has both sending and receiving relationships with other blocks, and there are more relationships with their own members. The second is the main benefit block. The main characteristic of this block is that the receiving relationship comes from both inside and outside the block, with the relationship from the outside of the block being clearly greater than the overflow to the outside of the block. The third is the net spillover block. The main characteristic of this block is that it receives significantly fewer connections from outside the block than it sends. The fourth is the broker block. The main characteristic of this block is that for other blocks, it has both receiving and sending relationships, and it has relatively few internal relationships within the block.

Based on the above analysis, a specific classification of the four major blocks was obtained as shown in Table 1.

Table 1. The specific classification of the four major blocks.

\begin{tabular}{ccc}
\hline \multirow{2}{*}{ Internal Relationship Ratio } & \multicolumn{2}{c}{ Received Relationship Ratio } \\
\cline { 2 - 3 } & ₹0 & $>\mathbf{0}$ \\
\hline$\geq\left(g_{k}-1\right) /(g-1)$ & bilateral spillover block & main benefit block \\
$<\left(g_{k}-1\right) /(g-1)$ & net spillover block & broker block \\
\hline
\end{tabular}

In Table 1 , assuming that block $G_{k}$ contains $g_{k}$ provinces, the total number of possible relationships within the block $G_{k}$ was $g_{k}\left(g_{k}-1\right)$. Throughout the spatial correlation network, the number of provinces is $g$, and therefore, the number of relationships that may exist in each province of the block $G_{k}$ in the spatial correlation network is $g_{k}(g-1)$. Therefore, the expected internal relationship ratio is $g_{k}\left(g_{k}-1\right) / g_{k}(g-1)=\left(g_{k}-1\right) /(g-1)$. 


\subsection{Variables and Data Sources}

\subsubsection{Input Variables}

When measuring GIE, this study considered "green" attributes on the basis of an accurate measurement of innovation efficiency. Because GIE considers innovation efficiency from the perspective of inputs, when considering innovation inputs, the energy input must also be considered.

The innovation inputs mainly include $R \& D$ personnel input and $R \& D$ capital input [16]. In this study, the full-time equivalent of research and experimental development personnel (RDP) was selected as a measure of R\&D personnel input, and the internal expenditure of research and experimental development expenditure (RDE) was used as R\&D.

The energy consumption converted into 10,000 tons of standard coal was selected as the measure of energy input.

\subsubsection{Output Variables}

The main output variables were the innovation and green outputs. Innovation is a process of technological creation and transformation. From the perspective of technological creation, the number of patent applications was selected as a measure of innovation output. From the perspective of technological transformation, the sales revenue of new products was selected as a measure of innovation output. In the production process, the formation of an innovative output often generates a certain degree of environmental pollution. Therefore, $\mathrm{SO}_{2}$ emissions were selected as a measure of environmental pollution.

The green innovation efficiency (GIE) measurement framework is showed at Figure 1.

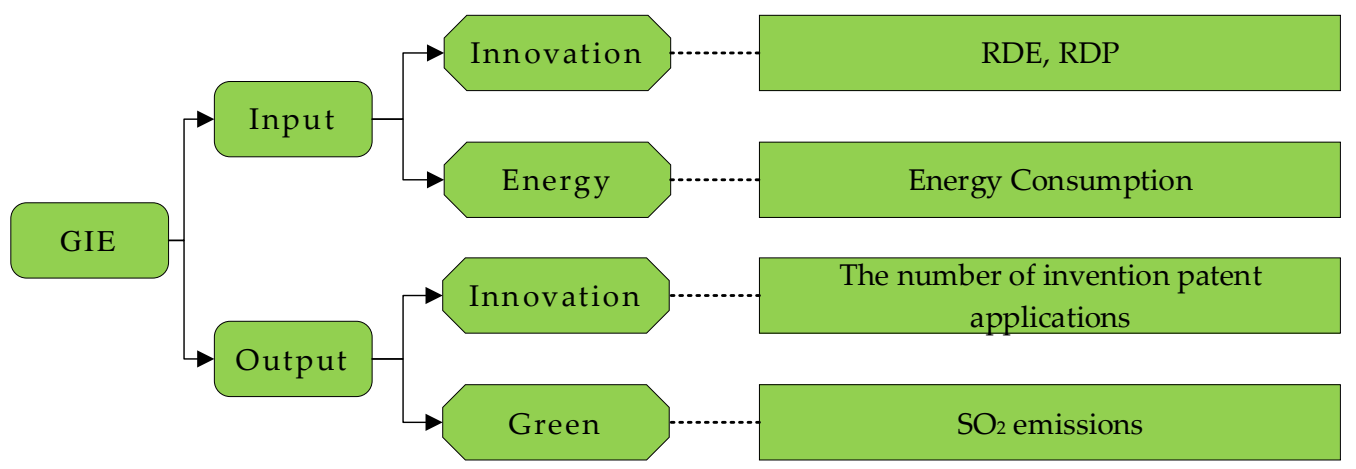

Figure 1. The green innovation efficiency (GIE) measurement framework.

\subsubsection{Data Sources}

Considering the completeness and availability of data, 30 provinces in China were selected for analysis over the period from 2009 to 2017 (the data for Tibet were not available, and it was, therefore, removed from the analysis). Data for the full-time equivalent of research and experimental development personnel, internal expenditure on research and experimental development, and the number of patent applications were obtained from the China Science and Technology Statistical Yearbook (2010-2018). The total energy consumption data converted into the standard coal equivalent were obtained from the China Energy Statistical Yearbook (2010-2018). The $\mathrm{SO}_{2}$ emissions data were obtained from the China Environmental Statistics Yearbook (2010-2018).

\section{Spatial Heterogeneity Analysis of GIE in China}

\subsection{Analysis of Spatial Distribution Characteristics}

The Super-EBM model was applied to measure China's GIE for each province from 2009 to 2017, and the results are shown in Table 2. 
Table 2. China's GIE measurement results.

\begin{tabular}{|c|c|c|c|c|c|c|c|c|c|c|}
\hline Province & 2009 & 2010 & 2011 & 2012 & 2013 & 2014 & 2015 & 2016 & 2017 & Mean \\
\hline Beijing & 0.542 & 0.507 & 0.642 & 0.653 & 0.78 & 0.871 & 0.868 & 1.008 & 1.044 & 0.768 \\
\hline Tianjin & 0.445 & 0.42 & 0.459 & 0.494 & 0.65 & 0.641 & 0.677 & 0.885 & 0.744 & 0.602 \\
\hline Hebei & 0.136 & 0.138 & 0.166 & 0.197 & 0.207 & 0.211 & 0.223 & 0.257 & 0.288 & 0.203 \\
\hline Shanghai & 0.485 & 0.513 & 0.64 & 0.642 & 0.656 & 0.705 & 0.69 & 0.869 & 1.058 & 0.695 \\
\hline Jiangsu & 0.317 & 0.365 & 0.617 & 0.74 & 0.857 & 0.877 & 0.878 & 1.006 & 1.002 & 0.740 \\
\hline Zhejiang & 0.327 & 0.307 & 0.423 & 0.482 & 0.603 & 0.671 & 0.762 & 1.001 & 1.004 & 0.620 \\
\hline Fujian & 0.225 & 0.224 & 0.266 & 0.272 & 0.283 & 0.287 & 0.318 & 0.473 & 0.502 & 0.317 \\
\hline Shandong & 0.274 & 0.296 & 0.327 & 0.391 & 0.524 & 0.572 & 0.642 & 0.639 & 0.567 & 0.470 \\
\hline Guangdong & 0.315 & 0.357 & 0.426 & 0.446 & 0.515 & 0.552 & 0.657 & 0.903 & 1.045 & 0.580 \\
\hline Hainan & 0.707 & 0.697 & 0.579 & 0.536 & 0.552 & 0.531 & 0.543 & 0.879 & 1.025 & 0.672 \\
\hline Liaoning & 0.216 & 0.202 & 0.287 & 0.318 & 0.384 & 0.317 & 0.332 & 0.385 & 0.373 & 0.313 \\
\hline Jilin & 0.423 & 0.296 & 0.351 & 0.287 & 0.182 & 0.267 & 0.301 & 0.447 & 0.519 & 0.341 \\
\hline Heilongjiang & 0.131 & 0.134 & 0.141 & 0.161 & 0.211 & 0.258 & 0.277 & 0.257 & 0.234 & 0.200 \\
\hline Shanxi & 0.142 & 0.141 & 0.164 & 0.177 & 0.185 & 0.177 & 0.186 & 0.244 & 0.258 & 0.186 \\
\hline Anhui & 0.221 & 0.256 & 0.334 & 0.394 & 0.514 & 0.638 & 0.768 & 1.01 & 1.015 & 0.572 \\
\hline Jiangxi & 0.166 & 0.184 & 0.208 & 0.243 & 0.275 & 0.289 & 0.317 & 0.439 & 0.517 & 0.293 \\
\hline Henan & 0.159 & 0.151 & 0.17 & 0.168 & 0.252 & 0.27 & 0.295 & 0.403 & 0.53 & 0.266 \\
\hline Hubei & 0.173 & 0.189 & 0.219 & 0.256 & 0.31 & 0.344 & 0.415 & 0.592 & 0.715 & 0.357 \\
\hline Hunan & 0.231 & 0.225 & 0.294 & 0.318 & 0.372 & 0.403 & 0.463 & 0.599 & 0.741 & 0.405 \\
\hline Inner Mongolia & 0.115 & 0.141 & 0.131 & 0.127 & 0.123 & 0.116 & 0.128 & 0.147 & 0.218 & 0.138 \\
\hline Guangxi & 0.235 & 0.209 & 0.229 & 0.283 & 0.455 & 0.569 & 0.783 & 1.021 & 1.006 & 0.532 \\
\hline Chongqing & 0.362 & 0.425 & 0.507 & 0.436 & 0.462 & 0.59 & 0.832 & 0.627 & 0.594 & 0.537 \\
\hline Sichuan & 0.184 & 0.159 & 0.22 & 0.224 & 0.281 & 0.315 & 0.401 & 0.514 & 0.559 & 0.317 \\
\hline Guizhou & 0.205 & 0.215 & 0.272 & 0.26 & 0.265 & 0.391 & 0.33 & 0.426 & 0.441 & 0.312 \\
\hline Yunnan & 0.183 & 0.18 & 0.185 & 0.179 & 0.185 & 0.201 & 0.191 & 0.219 & 0.214 & 0.193 \\
\hline Shaanxi & 0.173 & 0.194 & 0.243 & 0.269 & 0.357 & 0.324 & 0.244 & 0.303 & 0.556 & 0.296 \\
\hline Gansu & 0.159 & 0.175 & 0.212 & 0.233 & 0.241 & 0.271 & 0.268 & 0.25 & 0.254 & 0.229 \\
\hline Qinghai & 0.292 & 0.194 & 0.121 & 0.136 & 0.175 & 0.13 & 0.358 & 0.429 & 0.297 & 0.237 \\
\hline Ningxia & 0.216 & 0.214 & 0.209 & 0.251 & 0.373 & 0.313 & 0.389 & 0.346 & 0.373 & 0.298 \\
\hline Xinjiang & 0.146 & 0.191 & 0.178 & 0.184 & 0.217 & 0.264 & 0.272 & 0.287 & 0.277 & 0.224 \\
\hline China & 0.264 & 0.263 & 0.307 & 0.325 & 0.382 & 0.412 & 0.460 & 0.562 & 0.599 & 0.397 \\
\hline Eastern & 0.377 & 0.382 & 0.455 & 0.485 & 0.563 & 0.592 & 0.626 & 0.792 & 0.828 & 0.567 \\
\hline Central & 0.182 & 0.191 & 0.232 & 0.259 & 0.318 & 0.354 & 0.407 & 0.548 & 0.629 & 0.347 \\
\hline Western & 0.206 & 0.209 & 0.228 & 0.235 & 0.285 & 0.317 & 0.381 & 0.415 & 0.435 & 0.301 \\
\hline Northeast & 0.257 & 0.212 & 0.260 & 0.255 & 0.259 & 0.281 & 0.303 & 0.363 & 0.375 & 0.285 \\
\hline
\end{tabular}

It can be seen from Table 2 that from 2009 to 2017, the average GIE in China was 0.397, with average GIE values of 0.567 in the eastern region, 0.347 in the central region, and 0.301 in the western region. The average GIE value in the northeast region was 0.285.

The GIE in the eastern region was much higher than the national average, and there were large differences among the central, western, and northeastern regions, with values that were double that of the northeastern region. Most of the eastern region consists of coastal provinces, with unique geographical advantages in the development of innovation. The level of economic development is greater than that of the central, western, and northeastern regions. The level of innovative development is, therefore, the largest of anywhere in the country, and the allocation of scientific and technological resources has effectively stimulated innovation vitality. For the central, western, and northeastern regions, there is still a gap between the level of economic development and GIE when compared with the eastern region.

From the perspective of provinces, from 2009 to 2017, there were 10 provinces with a GIE higher than 0.5. These provinces in the order of high to low were Beijing, Jiangsu, Shanghai, Hainan, Zhejiang, Tianjin, Guangdong, Anhui, Chongqing, and Guangxi. Except for Anhui, Chongqing, and Guangxi, which were ranked relatively low, these provinces were all in the eastern region. The 12 provinces with an average GIE lower than 0.3 were 
Ningxia, Shaanxi, Jiangxi, Henan, Qinghai, Gansu, Xinjiang, Hebei, Heilongjiang, Yunnan, Shanxi, and Inner Mongolia. Only Hebei was located in the eastern region.

It can be seen from Figure 2 that China's GIE had a variable spatial distribution, with a decreasing trend from the east to the central, west, and northeast regions. In terms of temporal trends, in 2009, the provinces with the largest GIE were Beijing and Hainan. In 2013, the provinces with the largest GIE expanded to include Beijing, Tianjin, Shanghai, Jiangsu, and Zhejiang, with the gradual formation of small green innovation clusters. In 2017, China's GIE was large in Beijing, Tianjin, and across the southeast coastal provinces, which formed a cluster of green innovation. It was not clear if the formation of this agglomeration phenomenon was a random phenomenon or if it followed a certain internal law. It was, therefore, necessary to further explore the formation of this distribution.
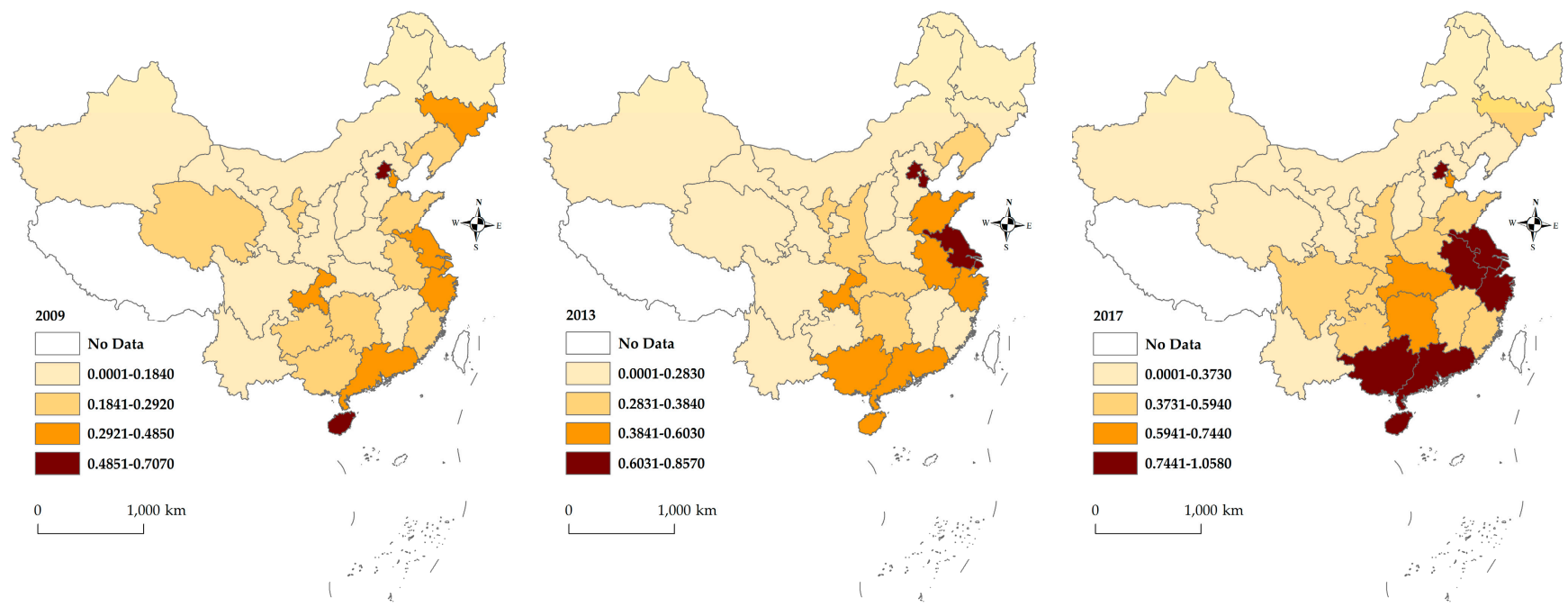

Figure 2. The spatial distribution of GIE in China in 2009, 2013, and 2017.

4.2. Spatial Autocorrelation Analysis of GIE

4.2.1. Global Spatial Autocorrelation Analysis of GIE

The global Moran index of China's GIE from 2009 to 2017 was calculated using ArcGIS 10.7, with the results shown in Figure 3.
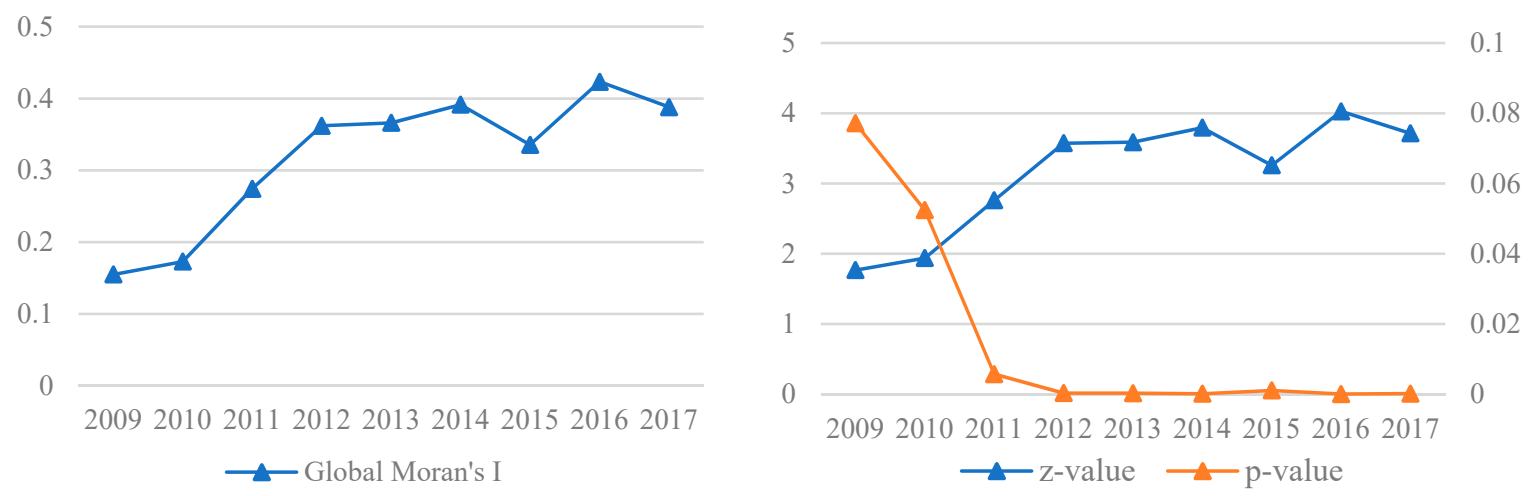

Figure 3. Global Moran index of GIE in China.

It can be seen from Figure 3 that from 2009 to 2017, at a significance level of $10 \%$, the global Moran index of China's GIE was greater than 0, which indicates that China's GIE was significantly spatially positively autocorrelated. Except for the slight decline in the Moran index values in 2015 and 2017, China's green innovation index displayed an upward trend in all other years, indicating that the positive spatial autocorrelation of China's GIE 
continuously increased. The links between green innovation activities in different provinces are constantly increasing, and they have strong spatial agglomeration characteristics.

\subsubsection{Local Spatial Autocorrelation Analysis of GIE}

We created a local Moran scatter diagram of China's GIE using GeoDa software, and analyzed its local agglomeration characteristics; we also identified its spatial correlation patterns. Due to space constraints, only a comparative analysis of 2009, 2013, and 2017 is reported here, as shown in Figure 4.

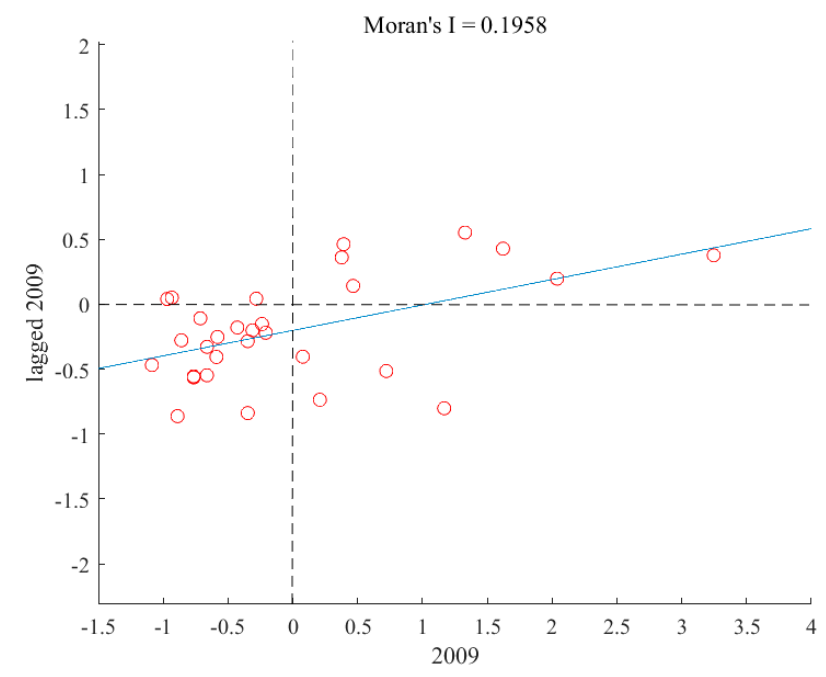

(a) 2009

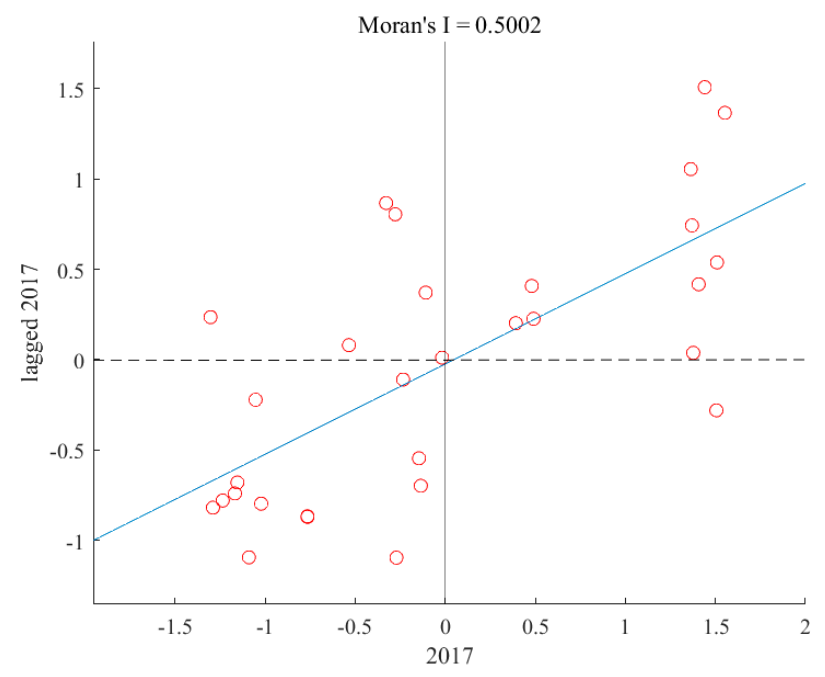

(b) 2017

Figure 4. Partial Moran scatter diagram of GIE in 2009 and 2017.

Figure 4 shows the local Moran's I scatter plots of China's GIE in 2009 and 2017. In the local Moran's I scatter plot, the first quadrant was the H-H spatial correlation pattern, i.e., high GIE-high spatial lag; the second quadrant was the L-H spatial correlation pattern, i.e., low GIE-high spatial lag; the third quadrant was the L-L spatial correlation pattern, i.e., low GIE-low spatial lag; and the fourth quadrant was the H-L spatial correlation pattern, i.e., high GIE-low spatial lag [62]. The clustering features of the first and third quadrants represented a positive spatial correlation, while the clustering features of the second and fourth quadrants represented a negative spatial correlation. In 2009, the GIE of 23 provinces had a positive spatial correlation, with seven of these provinces located in the first quadrant, displaying the $\mathrm{H}-\mathrm{H}$ spatial correlation pattern. In 2017, there were still 23 provinces with a positive spatial correlation in China's GIE, but the number of provinces displaying the $\mathrm{H}-\mathrm{H}$ spatial correlation patterns had increased to 10. This shows that GIE in most provinces had a positive spatial correlation with geographic space. Moreover, the slope of the regression fitting curve increased over time, indicating that the spatial correlation between GIE in different provinces had increased.

The forms of spatial agglomeration and temporal changes of GIE in various provinces were determined from a Moran's I scatter diagram (see Table 2 for details). It can be seen from the comparison and analysis that the provinces in which China's GIE exhibited a $\mathrm{H}-\mathrm{H}$ spatial correlation pattern were all economically developed regions in the east, among which Beijing, Tianjin, Hebei, Shanghai, Jiangsu, Zhejiang, Guangdong, and Hainan always displayed $\mathrm{H}-\mathrm{H}$ spatial correlation patterns throughout the study period. The provinces exhibiting the L-L spatial correlation pattern were all economically underdeveloped regions in the central, western, and northeast regions. Among them, Liaoning, Shanxi, Henan, Inner Mongolia, Guangxi, Sichuan, Shaanxi, Gansu, Ningxia, and Xinjiang always displayed the L-L spatial correlation pattern throughout the study period. Except for Liaoning, Shanxi, and Henan, all other provinces were economically underdeveloped areas in the west. The emergence of this type of agglomeration shows that China's high GIE provinces were 
concentrated in the eastern coastal areas, where regional innovation is developing rapidly, scientific and technological resources have been effectively allocated, and the highest level of GIE in the country has been achieved.

Figure 5 shows the changes in the temporal and spatial distribution of China's GIE in 2009 and 2017. The spatial dynamic transition process of GIE was further analyzed. This study applied the time-space transition measurement method used by Rey (2001) [63], and the different types of GIE dynamic transition were specifically expressed in the following categories. The first type was the transition of neighboring provinces in the relevant space. The form of GIE agglomeration in Heilongjiang changed from L-H to L-L, and the form of GIE agglomeration in Jiangxi, Guizhou, and Yunnan changed from L-L to L-H. The second type was a provincial transition of relative displacement. The form of GIE agglomeration in Hainan changed from L-H to $\mathrm{H}-\mathrm{H}$, the form of GIE agglomeration in Jilin and Qinghai changed from H-L to L-L, and the form of GIE agglomeration in Hubei changed from L-L to $\mathrm{H}-\mathrm{L}$. The third type was where the province and its neighboring provinces all transitioned to the form of other different provinces. For example, the form of GIE agglomeration of Shandong and Chongqing changed from H-L to L-H, and the form of GIE agglomeration in Anhui and Hunan hanged from L-L to H-H. The fourth type was where the province and its neighboring provinces remained at the same level, i.e., they remained unchanged throughout the inspection period. From 2009 to 2017, there were 18 provinces classed in the fourth transition type, accounting for $60 \%$ of the total. There was a stable GIE spatial distribution. The provinces with the highest GIE were still located on the eastern coast. However, with the adjustment of the allocation of scientific and technological resources and the promotion of relevant policies, the central and western provinces with a lower GIE will be led by their neighboring provinces with a higher GIE to improve their efficiency. To explore this dynamic transition process in depth, the spatial correlation network of GIE was then analyzed.
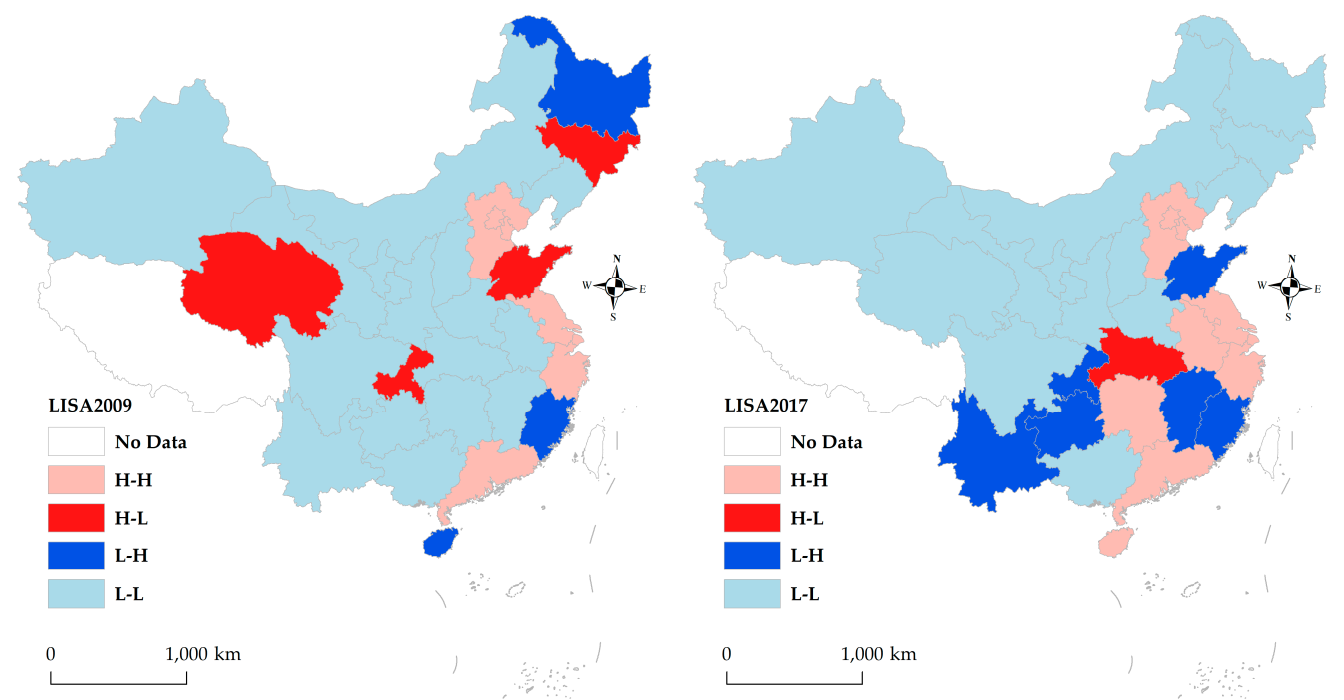

Figure 5. Spatial and temporal distribution changes of GIE in China based on Moran's I scatter plot in 2009, 2017.

\section{Analysis of the GIE Spatial Correlation Network}

\subsection{Establishment of the Spatial Correlation Network}

The ADF test on the GIE data revealed that the original data were not stable, but the data became stable after the first-order difference. According to Sadik-Zada and Gatto (2020) [64], we are supposed to conduct a cointegration test when we choose vector autoregression (VAR) or vector error correction model (VECM). Therefore, for the data 
after the first-order difference, we established a VAR model between two provinces, and determined the best lag period according to the Akaike Information Criterion (AIC), Schwarz Criterion (SC), and Hannan Quinn (HQ) criteria, and finally a Granger causality test was performed under the best lag period. The test results showed that the number of correlations among China's 30 provinces was 135. According to the results of this correlation, a spatial correlation network diagram was constructed (Figure 6).

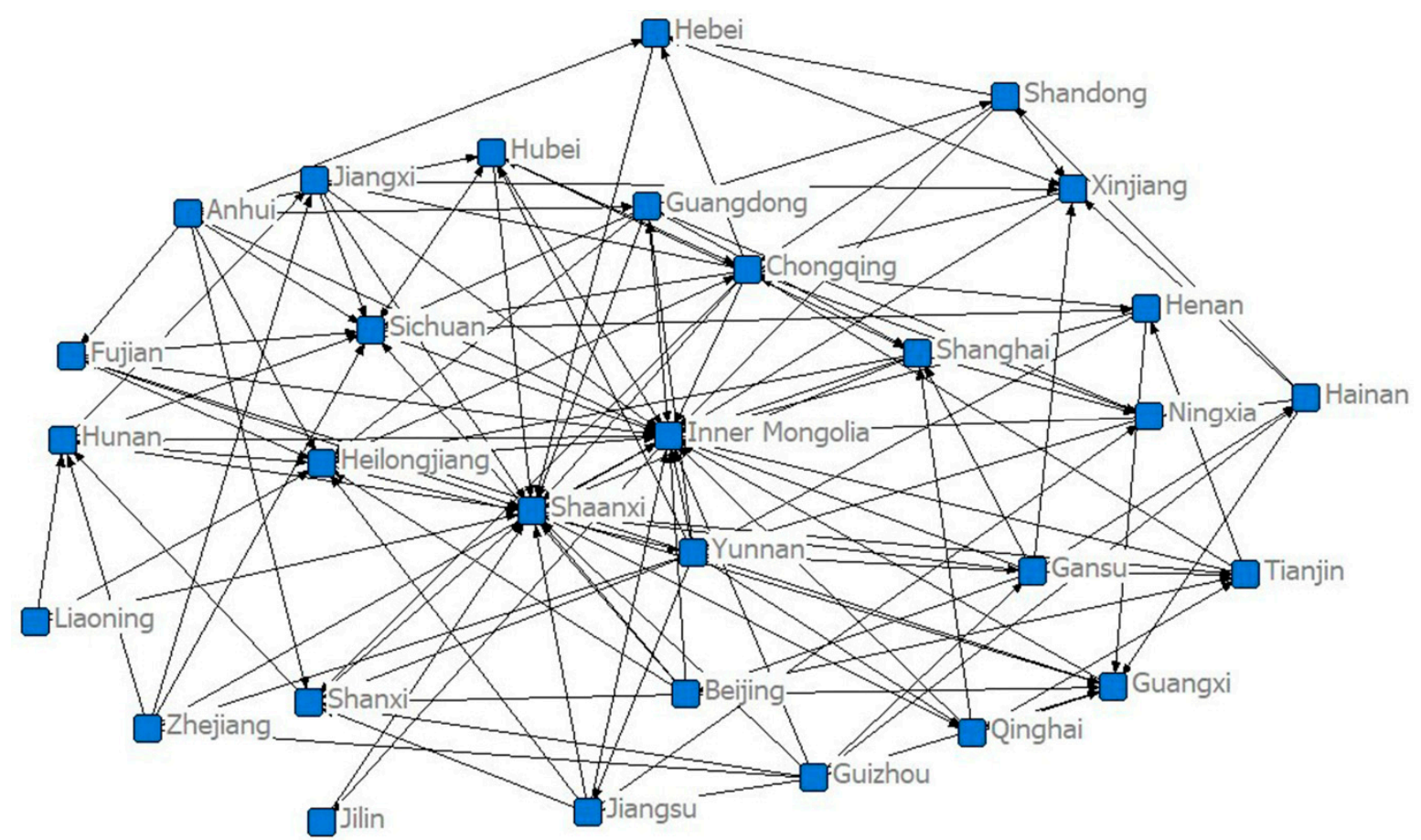

Figure 6. China's GIE spatial correlation network diagram.

From the spatial correlation network diagram, it can be seen that the spatial spillover channel of China's GIE was 135, and the number of correlations in each province was greater than 1, indicating that China's GIE was generally linked between different provinces.

\subsection{Spatial Correlation Network Characteristics}

Theoretically, the maximum number of relationships among China's 30 provinces was 870 , but the actual number of spatial relationships among China's provinces was 135. Therefore, the correlation network density in each province was 0.155 . The correlation was not strong, and there was still a lot of room for cooperation to improve GIE among various provinces.

There were two situations in the relationship between different provinces; one was the overflow relationship and the other was the benefit relationship. It can be seen from Table 3 that Inner Mongolia had the largest number of correlation relationships, 25, among which there were 24 beneficiary relationships and only one overflow relationship. Therefore, in general, Inner Mongolia and Shaanxi have benefited, while Anhui is overflowing. 
Table 3. Centrality analysis of the spatial correlation network of GIE.

\begin{tabular}{|c|c|c|c|c|c|c|c|}
\hline Region & Benefit & Spillover & Total & Region & Benefit & Spillover & Total \\
\hline Beijing & 2 & 7 & 9 & Jiangxi & 3 & 4 & 7 \\
\hline Tianjin & 4 & 4 & 8 & Henan & 2 & 4 & 6 \\
\hline Hebei & 4 & 2 & 6 & Hubei & 4 & 5 & 9 \\
\hline Shanghai & 4 & 4 & 8 & Hunan & 4 & 5 & 9 \\
\hline Jiangsu & 2 & 5 & 7 & Inner Mongolia & 24 & 1 & 25 \\
\hline Zhejiang & 2 & 4 & 6 & Guangxi & 5 & 5 & 10 \\
\hline Fujian & 2 & 4 & 6 & Chongqing & 7 & 8 & 15 \\
\hline Shandong & 2 & 4 & 6 & Sichuan & 9 & 3 & 12 \\
\hline Guangdong & 2 & 7 & 9 & Guizhou & 1 & 7 & 8 \\
\hline Hainan & 2 & 4 & 6 & Yunnan & 4 & 9 & 13 \\
\hline Liaoning & 0 & 3 & 3 & Shaanxi & 14 & 6 & 20 \\
\hline Jilin & 1 & 1 & 2 & Gansu & 3 & 6 & 9 \\
\hline Heilongjiang & 9 & 3 & 12 & Qinghai & 4 & 4 & 8 \\
\hline Shanxi & 6 & 2 & 8 & Ningxia & 4 & 3 & 7 \\
\hline Anhui & 0 & 8 & 8 & Xinjiang & 5 & 3 & 8 \\
\hline
\end{tabular}

Furthermore, a centrality analysis was conducted on the GIE spatial correlation network in 30 provinces in China, and the degree, closeness, and betweenness of each province were calculated (Figure 7). The degree centrality values of Inner Mongolia, Shaanxi, Yunnan, and Chongqing were among the highest values. In the GIE spatial correlation network, the largest number of correlations was directly related to these provinces, which were at the core of the spatial correlation network. Jilin and Liaoning had the lowest degree centrality, which indicated that their GIE has fewer correlations with other provinces. In terms of closeness, Inner Mongolia, Shaanxi, Chongqing, Yunnan, Heilongjiang, and Sichuan ranked highly, indicating that these provinces were not affected by other provinces in the GIE spatial correlation network. Provinces such as Liaoning, Hainan, and Jilin ranked low in closeness, indicating that these provinces had weak spatial correlations with other provinces and were at the edge of the spatial correlation network. For betweenness centrality, the ranking of provinces was similar to the results for closeness centrality. The standard deviation of the centrality of China's GIE spatial correlation network was 4.982, which was relatively large, indicating that there was a large imbalance in China's GIE spatial correlation network.
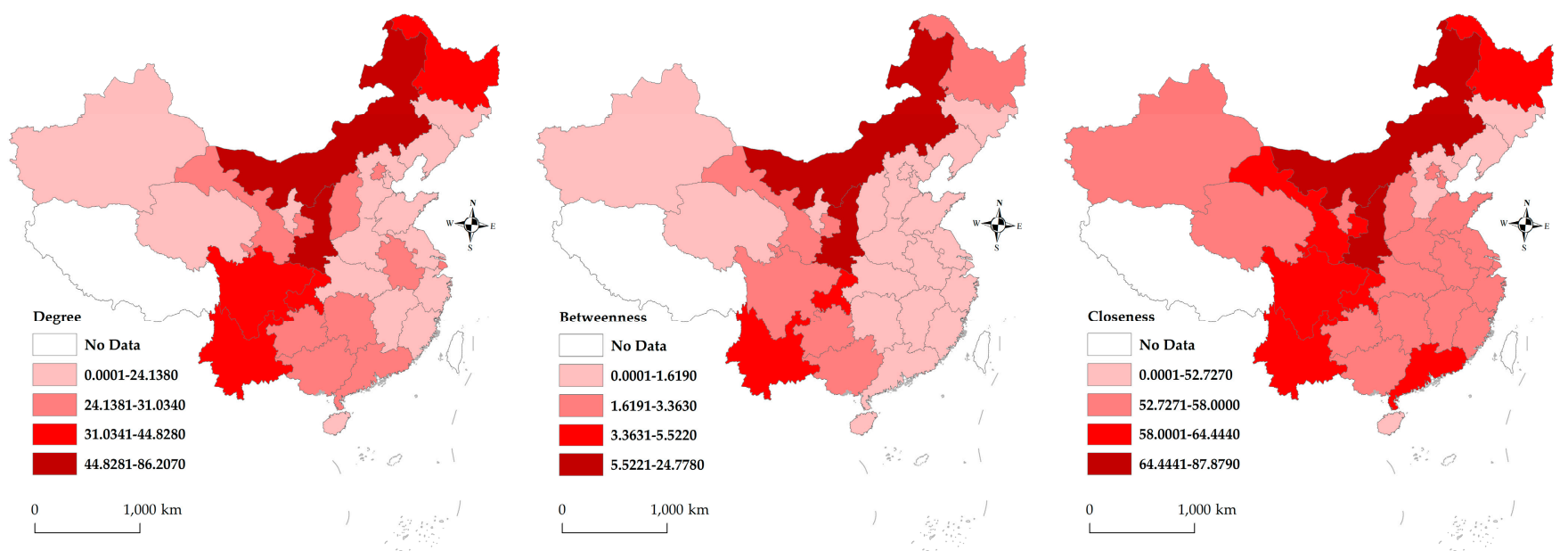

Figure 7. The spatial distribution of degree, betweenness, and closeness. 


\subsection{Spatial Correlation Network Block Model}

In the block model analysis of 30 provinces in China, UCINET was used to conduct a CONCOR analysis, the maximum segmentation depth was 2 , and the convergence standard was 0.200 . The division of GIE plates was obtained, with the provinces included in each block shown in Table 4.

Table 4. Province distribution of the four blocks.

\begin{tabular}{cl}
\hline Blocks & \multicolumn{1}{c}{ Region } \\
\hline First & Beijing, Guizhou, Yunnan, Shanghai, Jiangsu, Chongqing, Anhui \\
Second & Zhejiang, Jiangxi, Hebei, Liaoning, Jilin, Gansu, Shanxi, Fujian, Hunan, Guangdong, Hubei, Hainan \\
Third & Qinghai, Guangxi, Tianjin, Xinjiang, Henan, Shandong, Ningxia \\
Fourth & Inner Mongolia, Heilongjiang, Shaanxi, Sichuan \\
\hline
\end{tabular}

It can be seen from Table 5 that there were 18 internal correlations within the four GIE blocks among the 135 spatial correlations, and 117 correlations among the four GIE blocks, which indicates that there were very significant spillover relationships between the different blocks. The number of relationships issued by the first GIE block was 48 , of which the number of relationships belonging to the block was two, and the number of relationships received from other blocks was 18 . The expected ratio of internal relationships in this block was $21 \%$, while the actual ratio of internal relationships was $4 \%$. Therefore, the first GIE block mainly produced spillover effects on the outside of the block, which were classed as the "main spillover". The number of relationships issued by the second GIE block was 47, of which the number of relationships belonging to the block was six, and the number of relationships received from other blocks was 27 . The expected internal relationship ratio was $38 \%$, while the actual internal relationship ratio was $13 \%$. Therefore, the second GIE block was a typical "broker", which acted as a bridge and intermediary in the development of green innovation. The number of relationships issued by the third GIE block was 27, of which the number of relationships belonging to the block was seven, and the number of relationships received from other blocks was 19. The expected internal relationship ratio was $21 \%$, while the actual internal relationship ratio was $26 \%$. Therefore, the third GIE block produced a typical "bilateral spillover", and acted as a bridge and intermediary in the development of green innovation. The number of relationships issued by the fourth GIE block was 13, of which the number of relationships belonging to the block was three, and the number of relationships received from other blocks was 53 . The expected internal relationship ratio was $10 \%$, while the actual internal relationship ratio was $23 \%$. Therefore, the fourth GIE block was the recipient of net benefits.

Table 5. Analysis of spillover effects among the four blocks.

\begin{tabular}{|c|c|c|c|c|c|c|c|c|c|}
\hline \multirow{2}{*}{ Blocks } & \multicolumn{4}{|c|}{ Receiving Relationship } & \multirow{2}{*}{$\begin{array}{l}\text { Number of } \\
\text { Members }\end{array}$} & \multirow{2}{*}{$\begin{array}{l}\text { Expected Internal } \\
\text { Relation Ratio (\%) }\end{array}$} & \multirow{2}{*}{$\begin{array}{c}\text { Actual Internal } \\
\text { Relation Ratio (\%) }\end{array}$} & \multirow{2}{*}{$\begin{array}{l}\text { Received External } \\
\text { Relations }\end{array}$} & \multirow{2}{*}{ Feature } \\
\hline & First & Second & Third & Fourth & & & & & \\
\hline First & 2 & 21 & 5 & 20 & 7 & 21 & 4 & 18 & Main spillover \\
\hline Second & 5 & 6 & 10 & 26 & 12 & 38 & 13 & 27 & Broker \\
\hline Third & 11 & 2 & 7 & 7 & 7 & 21 & 26 & 19 & Bilateral spillover \\
\hline Fourth & 2 & 4 & 4 & 3 & 4 & 10 & 23 & 53 & Net benefit \\
\hline
\end{tabular}

Based on the different correlations between GIE blocks, a density matrix between each block was calculated, and the distribution of spillover effects between the different GIE blocks was analyzed.

The density matrix showed the distribution of GIE spillover effects. In the density matrix, the magnitude of the value and intensity of the spillover effect were proportional. It can be seen from Table 6 that the spillover effect of the first block was mainly reflected in the second and fourth blocks, and the spillover effects on the inside of the block and the third block were weak. The spillover effect of the second block was mainly reflected in the fourth block, and the spillover effect on other blocks was relatively weak. The spillover 
effect of the third block was mainly reflected in the first block, the interior of the third block, and the fourth block, and the spillover effect on the second block was relatively weak. The spillover effect of the fourth block was mainly reflected in the fourth block, and the spillover effect on other blocks was relatively weak.

Table 6. Density matrix of the four blocks.

\begin{tabular}{ccccc}
\hline & First & Second & Third & Fourth \\
\hline First & 0.048 & 0.25 & 0.102 & 0.714 \\
Second & 0.06 & 0.045 & 0.119 & 0.542 \\
Third & 0.224 & 0.024 & 0.167 & 0.25 \\
Fourth & 0.071 & 0.083 & 0.143 & 0.25 \\
\hline
\end{tabular}

The overall spatial correlation network density of the 30 provinces was 0.155 . If the density value in the density matrix of the four blocks was greater than 0.155 , then the density level was greater than the overall correlation network level, and the value was assigned to 1 , otherwise it was assigned to 0 . An image matrix was subsequently obtained, as shown in Table 7.

Table 7. Image matrix of the four blocks.

\begin{tabular}{ccccc}
\hline & First & Second & Third & Fourth \\
\hline First & 0 & 1 & 0 & 1 \\
Second & 0 & 0 & 0 & 1 \\
Third & 1 & 0 & 1 & 1 \\
Fourth & 0 & 0 & 0 & 1 \\
\hline
\end{tabular}

It can be seen from Table 7 that in the image matrix, not only was the diagonal assigned a value of 1 , but other positions were also assigned a value of 1 . This not only affected the interior of the GIE block but also had a spillover effect on other blocks.

Figure 8 shows the internal links between China's GIE blocks. Among them, the driving force of China's GIE is the third block. It is not only reflexive but also transmits GIE to the first and fourth blocks. The first block transmits GIE to the second and fourth blocks. The second block transmits GIE to the fourth block. The existence of this transmission mechanism reflects the significant "gradient" characteristics between the GIE blocks. The second block assumes the role of a bridge and is an intermediary in the transmission mechanism. The fourth block is only self-reflexive and only accepts spillover relationships from other blocks, realizing the agglomeration of GIE.

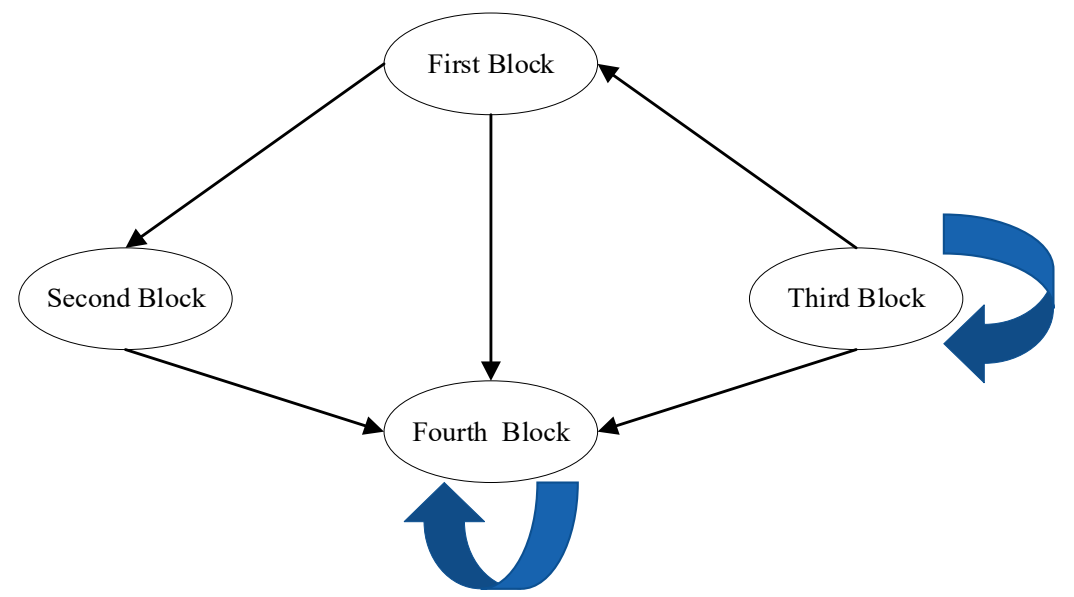

Figure 8. The relationship between GIE blocks. 


\section{Conclusions}

Based on the existing research, this study used a spatial autocorrelation analysis and social network analysis to explore the spatial correlation and devise a correlation network of China's GIE based on the provincial panel data of China from 2009 to 2017. First, the global Super-EBM model was used to measure GIE of 30 provinces in China, and the global spatial autocorrelation of GIE was analyzed through the global Moran index. Second, the local agglomeration characteristics of GIE were investigated through local Moran index scatter diagrams, and the temporal and spatial changes of China's GIE were determined through a time-space transition measurement method. Third, a spatial correlation network of China's GIE was then constructed through VAR and Granger causality test, and its overall characteristics were analyzed to determine the status and role of each province in the spatial correlation network. Finally, through the block model analysis method, the division of China's GIE and the internal correlation mechanism were analyzed. The following conclusions were drawn.

(1) There were large differences in the spatial distribution of China's GIE. The GIE in the east was much higher than the national average, with a gradual decrease from the eastern region to the central, western, and northeastern regions. From 2009 to 2017, China's GIE underwent a transformation from point and line to surface patterns. China's GIE is still spatially unbalanced, with a strong spatial heterogeneity. China's GIE presented a very significant spatial agglomeration feature, which was mainly manifested in a positive spatial correlation, i.e., provinces with a higher GIE tended to be closer to other provinces with a higher GIE.

(2) The analysis of local spatial autocorrelation showed that the economically developed areas in Eastern China had a H-H spatial correlation pattern, while in the underdeveloped western regions, there was an L-L spatial correlation pattern. The emergence of this spatial correlation model indicated that China's GIE remains spatially unbalanced and has significant spatial dependence characteristics.

(3) The characteristics of the spatial correlation network indicated that Inner Mongolia and Shaanxi were ranked relatively highly in degree centrality, betweenness centrality, and closeness centrality. In the GIE spatial correlation network, the largest number of relationships among provinces were directly related to these two provinces, and among its large number of correlation relationships, Inner Mongolia had the largest number of beneficiary relationships.

(4) Through a block model analysis, the GIE of China's provinces could be divided into four blocks, with different blocks bearing different responsibilities. The first block was mainly provinces with a high level of innovation and economic development, which were responsible for most of the GIE spillover. The second block was a broker, which assumed the responsibility of an intermediary in GIE. The third block was a bilateral spillover. It was the driving force of the four blocks. It was self-reflexive and transmitted the kinetic energy of GIE to the first and fourth blocks. The fourth block was provinces that acquired a net benefit by receiving spillover relationships from the first, second, and third blocks.

Based on the above conclusions, the following policy implications are provided. First, there is a need to maintain the level of GIE in the economically developed eastern regions, promote the transmission role of the central region, adjust the development mode of green innovation in the western and northeastern regions, drive the development of green innovation, and improve the level of GIE. Second, the administrative barriers preventing GIE should be broken down. This would improve the closeness of the relationship between different provinces and create more space for overflow channels. Finally, the central government should not only care about the main and bilateral spillover effects, as well as the power source that stimulates the spatial spillover effect but also be the broker that plays the role of intermediary. At the same time, there is a need to focus on the development level of green innovation as a net benefit to create a mor effective receiving platform for this net benefit. 
This study had some limitations, which should be pointed out. First, when analyzing GIE, the provincial level was used as the research unit, and the city was selected as the research unit in the subsequent research process. The spatial correlation network was more convincing. Only the block model was used to analyze the spillover effects of the regional GIE in China, although this could be combined with spatial measurements to analyze the convergence and spatial spillover effects of China's regional GIE.

Author Contributions: Both authors contributed to conceptualization, formal analysis, investigation, methodology, writing-original draft, and writing — review and editing. Both authors have read and agreed to the published version of the manuscript.

Funding: This research was funded by the National Natural Science Foundation of China (Nos. 71973131, 71973132 and 71403003), Major Project of National Social Science Foundation of China (No. 19VHQ002), and the Anhui Philosophy Social Science Planning Project (No. AHSKY2018D92).

Data Availability Statement: The data presented in this study are available in insert article.

Conflicts of Interest: The authors declare no conflict of interest.

\section{References}

1. Fan, W.; Hao, Y. An empirical research on the relationship amongst renewable energy consumption, economic growth and foreign direct investment in China. Renew. Energy 2020, 146, 598-609. [CrossRef]

2. Wu, D.; Wang, Y.; Qian, W. Efficiency evaluation and dynamic evolution of China's regional green economy: A method based on the Super-PEBM model and DEA window analysis. J. Clean. Prod. 2020, 264. [CrossRef]

3. Wang, Q.; Li, R. Decline in China's coal consumption: An evidence of peak coal or a temporary blip? Energy Policy 2017, 108, 696-701. [CrossRef]

4. Dong, C.-G.; Qi, Y.; Dong, W.-J.; Lu, X.; Liu, T.-L.; Qian, S. Decomposing driving factors for wind curtailment under economic new normal in China. Appl. Energy 2018, 217, 178-188. [CrossRef]

5. Lu, S.; Shen, J.H.; Li, W.; Zhang, J. A theory of economic development and dynamics of Chinese economy. Econ. Model. 2020, 86, 69-87. [CrossRef]

6. Liu, C.-Y.; Gao, X.; Ma, W.; Chen, X. Research on regional differences and influencing factors of green technology innovation efficiency of China's high-tech industry. J. Comput. Appl. Math. 2020, 369, 1-12. [CrossRef]

7. Huang, Y.-C.; Shi, Q.-P. Research on environmental efficiency and environmental total factor productivity in China's regional economies. China Popul. Resour. Environ. 2015, 25, 25-34.

8. Ren, Y.; Fang, C.; Li, G. Spatiotemporal characteristics and influential factors of eco-efficiency in Chinese prefecture-level cities: A spatial panel econometric analysis. J. Clean. Prod. 2020, 260. [CrossRef]

9. Li, D.; Zeng, T. Are China's intensive pollution industries greening? An analysis based on green innovation efficiency. J. Clean. Prod. 2020, 259, 120901. [CrossRef]

10. Aldieri, L.; Kotsemir, M.; Vinci, C.P. The role of environmental innovation through the technological proximity in the implementation of the sustainable development. Bus. Strategy Environ. 2020, 29, 493-502. [CrossRef]

11. Gatto, A. A pluralistic approach to economic and business sustainability: A critical meta-synthesis of foundations, metrics, and evidence of human and local development. Corp. Soc. Responsib. Environ. Manag. 2020, 27, 1525-1539. [CrossRef]

12. Jiang, Z.; Lyu, P.; Ye, L.; Zhou, Y.W. Green innovation transformation, economic sustainability and energy consumption during China's new normal stage. J. Clean. Prod. 2020, 273. [CrossRef]

13. Song, W.; Yu, H. Green innovation strategy and green innovation: The roles of green creativity and green organizational identity. Corp. Soc. Responsib. Environ. Manag. 2018, 25, 135-150. [CrossRef]

14. Zhang, F.; Zhu, L. Enhancing corporate sustainable development: Stakeholder pressures, organizational learning, and green innovation. Bus. Strategy Environ. 2019, 28, 1012-1026. [CrossRef]

15. Li, X.-J.; He, N. Regional competition environmental tax and enterprise green technology innovation. China Popul. Resour. Environ. 2018, 28, 73-81.

16. $\mathrm{Xu}, \mathrm{S}$.-R.; $\mathrm{Wu}, \mathrm{T}$;; Zhang, Y. The spatial-temporal variation and convergence of green innovation efficiency in the Yangtze River Economic Belt in China. Environ. Ence Pollut. Res. 2020, 27, 26868-26881. [CrossRef]

17. Miao, C.-L.; Fang, D.-B.; Sun, L.-Y.; Luo, Q.-L. Natural resources utilization efficiency under the influence of green technological innovation. Resour. Conserv. Recycl. 2017, 126, 153-161. [CrossRef]

18. Wang, W.-X.; Yu, B.; Yan, X.; Yao, X.-L.; Liu, Y. Estimation of innovation's green performance: A range-adjusted measure approach to assess the unified efficiency of China's manufacturing industry. J. Clean. Prod. 2017, 149, 919-924. [CrossRef]

19. Li, J.; Chen, S.; Wan, G.-H.; Fu, C.-M. Study on spatial correlation and explanation of regional economic growth in China: Based on analytic network process. Econ. Res. J. 2014, 49, 4-16.

20. Long, X.-L.; Sun, C.-W.; Wu, C.; Chen, B.; Boateng, K.A. Green innovation efficiency across China's 30 provinces: Estimate, comparison, and convergence. Mitig. Adapt. Strateg. Glob. Chang. 2019, 25, 1243-1260. [CrossRef] 
21. Mika, K. Dynamic environmental performance analysis: A Malmquist index approach. Ecol. Econ. 2008, 64, 701-715.

22. Cao, X.; Yu, J. Regional Innovation efficiency in China from the Green Low-carbon perspective. China Popul. Resour. Environ. 2015, 25, 10-19.

23. Farrell, M.J. The measurement of productive efficiency. J. R. Stat. Soc. 1957, 120, 253-290. [CrossRef]

24. Bai, J. On regional innovation efficiency: Evidence from panel data of China's different provinces. Reg. Stud. 2013, 47, 773-788. [CrossRef]

25. Bai, J.-H.; Li, J. Regional innovation efficiency in China: The role of local government. Innovation 2011, 13, 142-153. [CrossRef]

26. Chen, K.; Guan, J. Measuring the efficiency of China's regional innovation systems: Application of network data envelopment analysis (DEA). Reg. Stud. 2012, 46, 355-377. [CrossRef]

27. Min, S.; Kim, J.; Sawng, Y.-W. The effect of innovation network size and public R\&D investment on regional innovation efficiency. Technol. Forecast. Soc. Chang. 2020, 155. [CrossRef]

28. Zhang, J.X.; Kang, L.; Li, H.; Ballesteros-Perez, P.; Skitmore, M.; Zuo, J. The impact of environmental regulations on urban Green innovation efficiency: The case of Xi'an. Sustain. Cities Soc. 2020, 57. [CrossRef]

29. Zhang, Y.-B.; Jin, P.-Z.; Feng, D. Does civil environmental protection force the growth of China's industrial green productivity? Evidence from the perspective of rent-seeking. Ecol. Indic. 2015, 51, 215-227. [CrossRef]

30. Tao, X.-P.; Wang, P.; Zhu, B.-Z. Provincial green economic efficiency of China: A non-separable input-output SBM approach. Appl. Energy. 2016, 171, 58-66. [CrossRef]

31. Li, J.; Tan, Q.-M.; Bai, J.-H. Stochastic frontier analysis on the regional innovation efficiency of China. China Popul. Resour. Environ. 2009, 19, 142-147.

32. Oltra, V.; Saint, J.M. Sectoral systems of environmental innovation: An application to the French automotive industry. Technol. Forecast. Soc. Chang. 2009, 76, 567-583. [CrossRef]

33. Chiou, T.-Y.; Chan, H.K.; Lettice, F.; Chung, S.-H. The influence of greening the suppliers and green innovation on environmental performance and competitive advantage in Taiwan. Transp. Res. Part E Logist. Transp. Rev. 2011, 46, 822-836. [CrossRef]

34. Demirel, P.; Kesidou, E. Stimulating different types of eco-innovation in the UK: Government policies and firm motivations. Ecol. Econ. 2011, 70, 1546-1557. [CrossRef]

35. Hashimoto, A.; Haneda, S. Measuring the change in R\&D efficiency of the Japanese pharmaceutical industry. Res. Policy. 2008, 37, 1829-1836.

36. Lin, R.-J.; Tan, K.-H.; Geng, Y. Market demand, green product innovation, and firm performance: Evidence from Vietnam motorcycle industry. J. Clean. Prod. 2013, 40, 101-107. [CrossRef]

37. Sueyoshi, T.; Wang, D. Radial and non-radial approaches for environmental assessment by Data Envelopment Analysis: Corporate sustainability and effective investment for technology innovation. Energy Econ. 2014, 45, 537-551. [CrossRef]

38. Wong, C.Y.; Wong, C.W.Y.; Boon-itt, S. Effects of green supply chain integration and green innovation on environmental and cost performance. Int. J. Prod. Res. 2020, 58, 4589-4609. [CrossRef]

39. Feng, Z.-J.; Zeng, B.; Ming, Q. Environmental regulation, two-way foreign direct investment, and green innovation efficiency in China's manufacturing industry. Int. J. Environ. Res. Public Health. 2018, 15, 2292. [CrossRef]

40. Xue, Q.-Z.; Li, Q. Influences of multinational enterprises on local company's green innovation: A game theory analysis based on "green order effect". RED Manag. 2014, 26, 43-51.

41. Sellitto, M.A.; Camfield, C.G.; Buzuku, S. Green innovation and competitive advantages in a furniture industrial cluster: A survey and structural model. Sustain. Prod. Consum. 2020, 23, 94-104. [CrossRef]

42. Chan, R.Y.K.; He, H.-W.; Chan, H.-K.; Wang, W.Y.C. Environmental orientation and corporate performance: The mediation mechanism of green supply chain management and moderating effect of competitive intensity. Ind. Mark. Manag. 2012, 41, 621-630. [CrossRef]

43. Fu, G.; Lu, X.; Wu, C. Research on spatial pattern evolution of provincial green innovation in China. China Soft Sci. 2016, 7, 89-99.

44. Che, L.; Bai, Y.-P.; Zhou, L.; Wang, F.; Ji, X.-P.; Qiao, F.-W. Spatial pattern and spillover effects of green development efficiency in China. Sci. Geogr. Sin. 2018, 38, 1788-1798.

45. Luo, L.-W.; Liang, S.-R. Green technology innovation efficiency and factor decomposition of China's industrial enterprises. China Popul. Resour. Environ. 2016, 26, 149-157.

46. Lv, Y.-W.; Xie, Y.-X.; Lou, X.-J. Study on the convergence of China's regional green innovation efficiency. Sci. Technol. Prog. Policy. 2019, 36, 37-42.

47. Lv, Y.-W.; Xie, Y.-X.; Lou, X.-J. Study on the space-time transition and convergence trend of China's regional green innovation efficiency. J. Quant. Tech. Econ. 2020, 37, 78-97.

48. Du, J.-L.; Liu, Y.; Diao, W.-X. Assessing regional differences in green innovation efficiency of industrial enterprises in China. Int. J. Environ. Res. Public Health. 2019, 16, 940. [CrossRef]

49. Li, T.-C.; Liang, L.; Han, D.-R. Research on the efficiency of green technology innovation in China's provincial high-end manufacturing industry based on the RAGA-PP-SFA model. Math. Probl. Eng. 2018, 2018, 1-13. [CrossRef]

50. Ma, Y.; Yin, Q.-Y.; Pan, Y.-J.; Cui, W.; Xin, B.-J.; Rao, Z.-Q. Green product innovation and firm performance: Assessing the moderating effect of novelty-centered and efficiency-centered business model design. Sustainability 2018, 10, 1843. [CrossRef]

51. Bai, C.-Q.; Zhou, L.; Xia, M.-L.; Feng, C. Analysis of the spatial association network structure of China's transportation carbon emissions and its driving factors. J. Environ. Manag. 2020, 253, 109765. [CrossRef] 
52. Deng, Q.-Z.; Zhou, S.-Z.; Peng, F. Measuring green innovation efficiency for china's high-tech manufacturing industry: A network DEA approach. Math. Probl. Eng. 2020, 2020, 13. [CrossRef]

53. Agovino, M.; Cerciello, M.; Gatto, A. Policy efficiency in the field of food sustainability. The adjusted food agriculture and nutrition index. J. Environ. Manag. 2018, 218, 220-233. [CrossRef] [PubMed]

54. Tone, K. A slacks-based measure of super-efficiency in data envelopment analysis. Eur. J. Oper. Res. 2002, 143, 32-41. [CrossRef]

55. Qin, Q.-D.; Li, X.; Li, L.; Zhen, W.; Wei, Y.-M. Air emissions perspective on energy efficiency: An empirical analysis of China's coastal areas. Appl. Energy. 2017, 185, 604-614. [CrossRef]

56. Tone, K.; Tsutsui, M. An epsilon-based measure of efficiency in DEA: A third pole of technical efficiency. Eur. J. Oper. Res. 2010, 207, 1554-1563. [CrossRef]

57. Yu, H.-S.; Song, G.; Li, T.; Liu, Y.-J. Spatial pattern characteristics and influencing factors of green use efficiency of urban construction land in Jilin province. Complexity 2020, 2020, 1-12. [CrossRef]

58. Sadik-Zada, E.R. Oil Abundance and Economic Growth; Logos Verlag Berlin GmbH: Berlin, Germany, 2016.

59. Freeman, L.C. Centrality in social networks conceptual clarification. Soc. Netw. 1979, 1, 215-239. [CrossRef]

60. White, H.C.; Boorman, S.A.; Breiger, R.L. Social structure from multiple networks: I. Block models of roles and positions. Am. J. Sociol. 1976, 81, 730-779. [CrossRef]

61. Zhang, W.-P.; Zhuang, X.-T.; Wu, D.-M. Spatial connectedness of volatility spillovers in G20 stock markets: Based on block models analysis. Financ. Res. Lett. 2020, 34. [CrossRef]

62. Zhao, X.-F.; Huang, X.-J.; Liu, Y.-B. Spatial autocorrelation analysis of Chinese inter-provincial industrial chemical oxygen demand discharge. Int. J. Environ. Res. Public Health. 2012, 9, 2031-2044. [CrossRef] [PubMed]

63. Rey, S.J. Spatial empirics for economic growth and convergence. Geogr. Anal. 2001, 33, 195-214. [CrossRef]

64. Sadik-Zada, E.R.; Gatto, A. The puzzle of greenhouse gas footprints of oil abundance. Socio-Econ. Plan. Sci. 2020, 100936. [CrossRef] 